Article

\title{
A New Method for the Synthesis of Heterospin Complexes
}

\author{
Victor Ovcharenko *, Olga Kuznetsova, Elena Fursova, Galina Romanenko \\ and Artem Bogomyakov
}

International Tomography Center, Siberian Branch of the Russian Academy of Sciences, Institutskaya Str., 3a, Novosibirsk 630090, Russia; E-Mails: olya@tomo.nsc.ru (O.K.); fursova@tomo.nsc.ru (E.F.); romanenko@tomo.nsc.ru (G.R.); bus@tomo.nsc.ru (A.B.)

* Author to whom correspondence should be addressed; E-Mail: Victor.Ovcharenko@tomo.nsc.ru; Tel.: +7-383-333-1945.

Academic Editors: Martin T. Lemaire and Helmut Cölfen

Received: 21 September 2015 / Accepted: 20 November 2015 / Published: 2 December 2015

\begin{abstract}
The interaction of binuclear $\mathrm{Co}(\mathrm{II})$ pivalate $\left[\mathrm{Co}_{2}\left(\mathrm{H}_{2} \mathrm{O}\right) \mathrm{Piv}_{4}(\mathrm{HPiv})_{4}\right]$ with nitronyl nitroxide $\mathrm{HL}^{1}$ (2-(2-hydroxy-5-nitrophenyl)-4,4,5,5-tetramethyl-4,5-dihydro-1H-imidazole3-oxide-1-oxyl) in organic solvents led to the formation of a pentanuclear heterospin complex [Co5(Piv) ${ }_{4} \mathrm{~L}^{1}{ }_{4} \mathrm{~L}^{2}{ }_{2}$ ]. A nontrivial peculiarity of the complex is the presence of both the starting nitronyl nitroxide $\mathrm{L}^{1}$ and its deoxygenated derivative imino nitroxide $\mathrm{L}^{2}\left(\mathrm{HL}^{2}\right.$ : 2-(2-hydroxy-5-nitrophenyl)-4,4,5,5-tetramethyl-4,5-dihydro-1H-imidazole-1-oxyl) in its coordination sphere. Based on this, a new synthetic approach was developed, which suggests the use of both the starting radical and the product of its reduction in the reaction with the metal. The suggested approach is a new method for the synthesis of heterospin compounds, including those that cannot be obtained by other methods. It was shown that the reaction of $\mathrm{Co}(\mathrm{II})$ pivalate with a mixture of $\mathrm{HL}^{1}$ and $\mathrm{HL}^{2}$ can give a trinuclear heterospin complex [Co3(Piv) ${ }_{2} \mathrm{~L}_{2}{ }_{2} \mathrm{~L}_{2}{ }_{2}$. The replacement of $\mathrm{Co}$ (II) by $\mathrm{Ni}$ (II) completely suppresses the reduction of $\mathrm{HL}^{1}$ into $\mathrm{HL}^{2}$, and $\mathrm{Ni}(\mathrm{II})$ pivalate does not react with $\mathrm{HL}^{1}$. The use of a known mixture of $\mathrm{HL}^{1}$ and $\mathrm{HL}^{2}$ in the reaction with $\left[\mathrm{Ni}_{2}\left(\mathrm{H}_{2} \mathrm{O}\right) \mathrm{Piv}_{4}(\mathrm{HPiv})_{4}\right]$, however, led to the formation of a heterospin complex $\left[\mathrm{Ni}_{3} \mathrm{~L}^{1} \mathrm{~L}^{2}{ }_{2}(\mathrm{Piv})_{3}(\mathrm{HPiv})_{3}\right]$ also containing both nitronyl nitroxide and imino nitroxide.
\end{abstract}

Keywords: cobalt(II); nickel(II); nitronyl nitroxide; imino nitroxide; redox transformation; new synthetic approach 


\section{Introduction}

Nitroxides have found wide use when solving fundamental problems [1,2]. They are used in radical-mediated polymerization [3,4], for creating rechargeable organic batteries $[5,6]$, as contrast agents for magnetic resonance imaging [7-9] and as organic paramagnets in the synthesis of heterospin molecular magnets [10-16]. Transition metal complexes with nitroxides were used to create heterospin breathing crystals [17]. Nitroxides are widely used in biology, biochemistry and medicine [18-20]. Their behavior in reactions with organic C-centered radicals was actively studied [21]. They are also widely used in the synthesis of various organic derivatives in polymer chemistry [22].

Recently, an unusual process called a "redox-induced change in the ligand coordination mode" was recorded. While reacting with a transition metal, imino nitroxide $\mathrm{HL}^{2}$ (Scheme 1) showed multifunctional behavior, namely, while reacting with cobalt pivalate, some 2-(2-hydroxy-5-nitrophenyl)-4,4,5,5-tetramethyl-4,5-dihydro-1H-imidazole-1-oxyl ( $\left.\mathrm{HL}^{2}\right)$ molecules were reduced to the corresponding nitrone $\mathrm{HL}^{3}$ (2-(2-hydroxy-5-nitrophenyl)-4,4,5,5-tetramethyl-4,5dihydro-1H-imidazole-3-oxide), and an unusual solid product $\left[\mathrm{Co} 3(\mathrm{Piv})_{2} \mathrm{~L}_{2}^{2} \mathrm{~L}^{3} 2\right]$ containing both the starting imino nitroxide and its reduced diamagnetic analog was isolated. The redox process led to a change not only in the electronic state of the ligand, but also in its coordination mode [23]. The very fact of the formation of $\left[\mathrm{Co} 3(\mathrm{Piv})_{2} \mathrm{~L}_{2} \mathrm{~L}^{3} 2\right]$ indicates that there exists an individual class of metal compounds with nitroxides whose ligand shell contains both the starting radical and the product of its reduction.

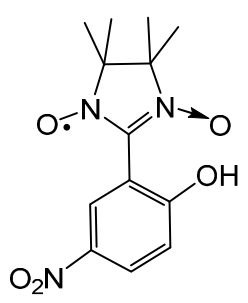

$\mathrm{HL}^{1}$

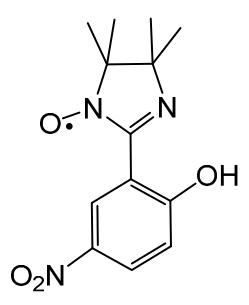

$\mathrm{HL}^{2}$

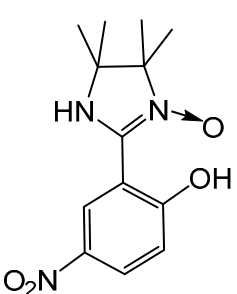

$\mathrm{HL}^{3}$

Scheme 1. Nitronyl nitroxide 2-(2-hydroxy-5-nitrophenyl)-4,4,5,5-tetramethyl-4,5-dihydro1H-imidazole-3-oxide-1-oxyl ( $\left.\mathrm{HL}^{1}\right)$, imino nitroxide 2-(2-hydroxy-5-nitrophenyl)-4,4,5,5tetramethyl-4,5-dihydro-1H-imidazole-1-oxyl $\left(\mathrm{HL}^{2}\right)$ and amidine oxide 2-(2-hydroxy-5nitrophenyl)-4,4,5,5-tetramethyl-4,5-dihydro-1H-imidazole-3-oxide $\left(\mathrm{HL}^{3}\right)$ molecules.

The present paper describes the pentanuclear multispin complex [Co5 $(\mathrm{Piv})_{4} \mathrm{~L}_{4}^{1} \mathrm{~L}^{2} 2$ formed in the reaction of $\mathrm{Co}(\mathrm{II})$ pivalate with nitronyl nitroxide 2-(2-hydroxy-5-nitrophenyl)-4,4,5,5-tetramethyl-4,5dihydro-1H-imidazole-3-oxide-1-oxyl $\left(\mathrm{HL}^{1}\right)$. The composition of the complex indicates that some part of $\mathrm{HL}^{1}$ is reduced to $\mathrm{HL}^{2}$ during the reaction, because the isolated product contains two radicals: the starting nitronyl nitroxide and its reduced derivative, the corresponding imino nitroxide. In contrast to $\mathrm{Co}(\mathrm{II})$ pivalate, $\mathrm{Ni}$ (II) pivalate does not react with $\mathrm{HL}^{1}$ under similar conditions and does not convert it into $\mathrm{HL}^{2}$, but the reaction of $\mathrm{Ni}$ (II) pivalate with a mixture of $\mathrm{HL}^{1}$ and $\mathrm{HL}^{2}$ leads to the formation of a heterospin complex $\left[\mathrm{Ni}_{3} \mathrm{~L}^{1} \mathrm{~L}_{2}{ }_{2}(\mathrm{Piv})_{3}(\mathrm{HPiv})_{3}\right]$ also containing coordinated anions of both nitroxides. Based on the obtained data, a new approach to the synthesis of heterospin compounds is suggested: the reaction of both nitronyl nitroxide and imino nitroxide with the metal. This allowed purposeful synthesis of the $\left[\mathrm{Co}_{3}(\mathrm{Piv})_{2} \mathrm{~L}_{2}{ }_{2} \mathrm{~L}_{2}{ }_{2}\right]$ trinuclear complex containing two different radicals in the coordination shell. 


\section{Results and Discussion}

The synthesis of trinuclear $\left[\mathrm{Co}_{3}(\mathrm{Piv})_{2} \mathrm{~L}_{2}^{2} \mathrm{~L}^{3}{ }_{2}\right]$, where $\mathrm{L}^{2}$ is the imino nitroxide 2-(2-hydroxy-5-nitrophenyl)-4,4,5,5-tetramethyl-4,5-dihydro- $1 \mathrm{H}$-imidazole-1-oxyl anion and $\mathrm{L}^{3}$ is the corresponding amidine oxide anion (Scheme 1), was described in [23]. The isolation of this compound was a nontrivial problem, because $\left[\mathrm{Co}_{3}(\mathrm{Piv})_{2} \mathrm{~L}_{2}{ }_{2} \mathrm{~L}^{3}{ }_{2}\right]$ crystallized from the reaction mixture only when the starting reagents were used in a strictly definite ratio. In addition, other compounds crystallized along with the desired product, from which they were sometimes separated mechanically. A good yield of $\left[\mathrm{Co}_{3}(\mathrm{Piv})_{2} \mathrm{~L}_{2}{ }_{2} \mathrm{~L}^{3}{ }_{2}\right]$ in the individual state was obtained only when $\mathrm{Co}$ (II) pivalate and an equimolar mixture of $\mathrm{HL}^{2}$ and $\mathrm{HL}^{3}$ were used as reagents. This should be taken into account, because below, we make a certain analogy between the reaction of $\mathrm{Co}(\mathrm{II})$ pivalate with a mixture of $\mathrm{HL}^{2}$ and $\mathrm{HL}^{3}$ and the reaction of $\mathrm{Co}$ (II) pivalate with a mixture of $\mathrm{HL}^{1}$ and $\mathrm{HL}^{2}$.

In the heterospin [ $\left.\mathrm{Co}_{3}(\mathrm{Piv})_{2} \mathrm{~L}_{2}{ }_{2} \mathrm{~L}_{2}^{3}\right]$ molecule, both $\mathrm{L}^{2}$ 's perform the function of terminal chelate ligands, which form six-membered metallocycles typical for Schiff bases. The $\mathrm{L}^{3}$ anions are coordinated as bridging tetradentate ligands; the "central" cobalt atom forms seven-membered metallocycles with them (Scheme 2).

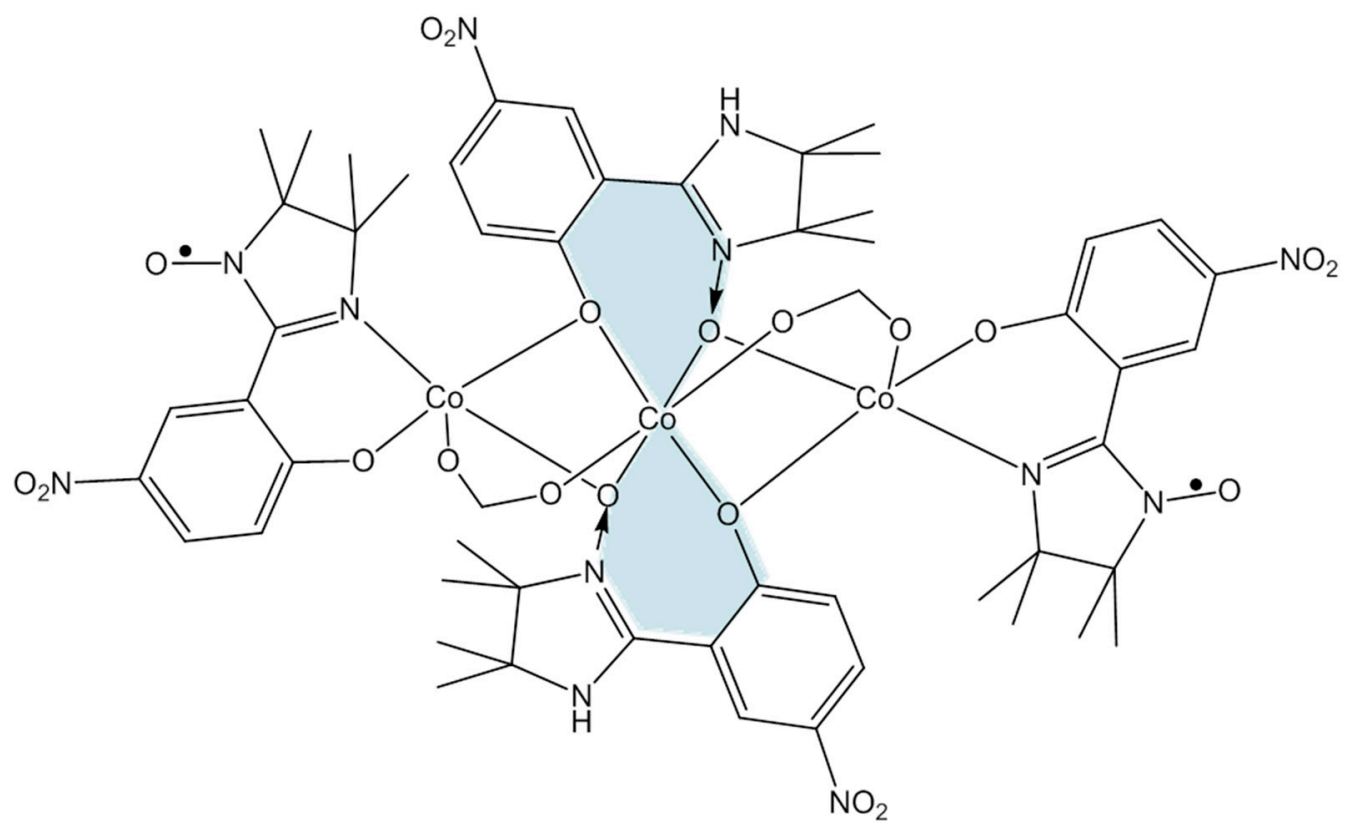

Scheme 2. Seven-membered metallocycles formed by $\mathrm{L}^{3}$ with the "central" cobalt atoms in the trinuclear $\left[\mathrm{Co} 3(\mathrm{Piv})_{2} \mathrm{~L}_{2}^{2} \mathrm{~L}_{2}^{3}\right]$ molecule.

We noticed that the $\mathrm{L}^{3}$ donor group that formed seven-membered metallocycles in the $\left[\mathrm{Co} 3(\mathrm{Piv})_{2} \mathrm{~L}_{2}{ }_{2} \mathrm{~L}_{2}^{3}\right]$ molecule (Scheme 2) was identical to that in nitronyl nitroxide $\mathrm{HL}^{1}$. This prompted us to study the product of the interaction of $\mathrm{Co}(\mathrm{II})$ pivalate with the equimolar mixture of $\mathrm{HL}^{1}$ and $\mathrm{HL}^{2}$. The isostructural character of the $\mathrm{L}^{1}$ and $\mathrm{L}^{3}$ donor group (Scheme 3) was assumed to be favorable for purposeful introduction of $\mathrm{L}^{1}$ in the complex molecule to ultimately obtain a multispin complex containing two different paramagnetic ligands. 


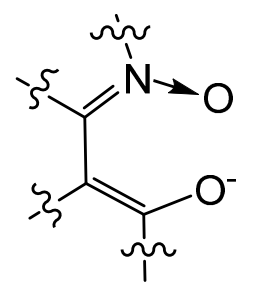

Scheme 3. The $\mathrm{L}^{1}$ and $\mathrm{L}^{3}$ donor group, which is favorable for the formation of seven-membered metallocycles.

Indeed, the reaction of binuclear Co(II) pivalate with a mixture of nitroxides $\mathrm{HL}^{1}$ and $\mathrm{HL}^{2}$ gave a trinuclear $\left[\mathrm{Co}_{3}(\mathrm{Piv})_{2} \mathrm{~L}_{2}{ }_{2} \mathrm{~L}_{2}^{2}\right]$ complex, which contained both nitroxides. The maximum yield of the product $(70 \%)$ was obtained at a molar ratio of reagents $\left[\mathrm{Co}_{2}\left(\mathrm{H}_{2} \mathrm{O}\right)(\mathrm{Piv})_{4}(\mathrm{HPiv})_{4}\right]: \mathrm{HL}^{1}: \mathrm{HL}^{2}=3: 4: 4$, corresponding to the stoichiometric coefficients of the reaction:

$$
3\left[\mathrm{Co}_{2}\left(\mathrm{H}_{2} \mathrm{O}\right)(\mathrm{Piv}) 4(\mathrm{HPiv})_{4}\right]+4 \mathrm{HL}^{1}+4 \mathrm{HL}^{2}=2\left[\mathrm{Co}_{3}(\mathrm{Piv})_{2} \mathrm{~L}^{1}{ }_{2} \mathrm{~L}^{2}{ }_{2}\right]+20 \mathrm{HPiv}+3 \mathrm{H}_{2} \mathrm{O}
$$

The trinuclear molecule of the complex (Figure 1), which crystallized as a solvate with two acetone molecules [ $\left.\mathrm{Co}_{3}(\mathrm{Piv})_{2} \mathrm{~L}_{2}{ }_{2} \mathrm{~L}^{2}{ }_{2}\right] \cdot 2 \mathrm{Me}{ }_{2} \mathrm{CO}$, is isostructural with [Co3(Piv) ${ }_{2} \mathrm{~L}_{2}{ }_{2} \mathrm{~L}^{3}$ ]. The "terminal" cobalt atoms form six-membered metallocycles with the coordinated imino nitroxides. The "central" Co atom forms seven-membered metallocycles with nitronyl nitroxides, which perform the cyclic bridging tetradentate function. The trigonal-bipyramidal environment of the terminal cobalt atoms is formed by the $\mathrm{N}$ atom of the nitroxyl fragment (Co1-N1R 2.024(3) $\AA$ ), two Oph atoms of the phenoxy groups $\mathrm{L}^{2}$ and $\mathrm{L}^{1}$, the Opiv atom and the bridging $\mathrm{O}_{\mathrm{NO}}$ atom of the nitroxyl group $\mathrm{L}^{1}$ at distances of $1.907(2)-2.311(3) \AA$. The octahedral environment of $\mathrm{Co}_{2}$ (the symmetry of the environment is $C_{2}$ ) is formed by two Opiv (2.042(2) $\AA$ ), two $\mu$-ONO $(2.033(2) \AA)$ and two $\mu$-Oph $(2.108(2) \AA)$ atoms.

Thus, the interaction of $\mathrm{Co}$ (II) pivalate with an equimolar mixture of nitronyl and imino nitroxides is an effective method for the synthesis of the heterospin $\left[\mathrm{Co}_{3}(\mathrm{Piv})_{2} \mathrm{~L}_{2}{ }_{2} \mathrm{~L}_{2}{ }_{2}\right.$ ] complex containing two different paramagnetic ligands.

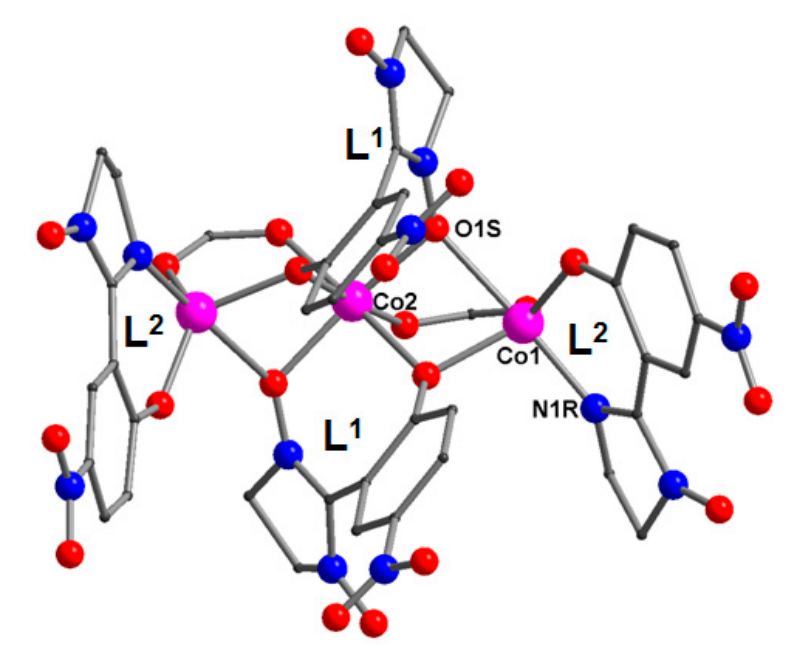

Figure 1. Trinuclear [ $\mathrm{Co}_{3}(\mathrm{Piv})_{2} \mathrm{~L}_{2} \mathrm{~L}_{2}^{2}$ ] molecule. Hereinafter, small black balls, C; magenta, $\mathrm{Co}$; red, $\mathrm{O}$; blue, $\mathrm{N}$; the $\mathrm{H}$ atoms and the $\mathrm{CH}_{3}$ and $\mathrm{Bu}^{\mathrm{t}}$ groups are omitted. 
If imino nitroxide is not introduced in the reaction mixture and only nitronyl nitroxide $\mathrm{HL}^{1}$ is used in the reaction with $\mathrm{Co}(\mathrm{II})$ pivalate, the solid product is the pentanuclear heterospin compound $\left[\mathrm{Co} 5(\mathrm{Piv})_{4} \mathrm{~L}_{4}{ }_{4} \mathrm{~L}_{2}^{2}\right] \cdot 0.5 \mathrm{Me}_{2} \mathrm{CO} \cdot 0.5 \mathrm{C}_{7} \mathrm{H}_{16}$. It also contains nitroxides $\mathrm{L}^{1}$ and $\mathrm{L}^{2}$ in the ligand shell. In this case, $\mathrm{L}^{2}$ forms as a consequence of the redox process, in which $\mathrm{L}^{1}$ is deoxygenated. The complex forms by the reaction of cobalt pivalate with $\mathrm{HL}^{1}$ in an acetone/heptane mixture with an initial ratio of reagents $\left[\mathrm{Co}_{2}\left(\mathrm{H}_{2} \mathrm{O}\right) \mathrm{Piv}_{4}(\mathrm{HPiv})_{4}\right]: \mathrm{HL}^{1}$ from 1:1-1:4; the product yield can reach 50\%-60\%. The maximum yield of $\left[\mathrm{Co} 5(\mathrm{Piv})_{4} \mathrm{~L}_{4}^{1} \mathrm{~L}_{2}^{2}\right] \cdot 0.5 \mathrm{Me}_{2} \mathrm{CO} \cdot 0.5 \mathrm{C}_{7} \mathrm{H}_{16}(70 \%)$ was achieved in an alternative synthesis in one of the experiments at an initial molar ratio of reagents of $\left[\mathrm{Co}_{2}\left(\mathrm{H}_{2} \mathrm{O}\right)(\mathrm{Piv})_{4}(\mathrm{HPiv})_{4}\right]: \mathrm{HL}^{1}: \mathrm{HL}^{2}=5: 8: 4$, corresponding to the stoichiometric coefficients of the reaction:

$$
5\left[\mathrm{Co}_{2}\left(\mathrm{H}_{2} \mathrm{O}\right) \mathrm{Piv}_{4}(\mathrm{HPiv})_{4}\right]+8 \mathrm{HL}^{1}+4 \mathrm{HL}^{2}=2\left[\mathrm{Co} 5(\mathrm{Piv})_{4} \mathrm{~L}^{1}{ }_{4} \mathrm{~L}_{2}{ }_{2}\right]+32 \mathrm{HPiv}+5 \mathrm{H}_{2} \mathrm{O}
$$

Note, however, that the use of the known mixture of $\mathrm{HL}^{1}$ and $\mathrm{HL}^{2}$ with the indicated reagent ratio in the synthesis often leads to crystallization of a mixture of [Cos( $\left.\mathrm{Piv})_{4} \mathrm{~L}^{1}{ }_{4} \mathrm{~L}^{2}{ }_{2}\right] \cdot 0.5 \mathrm{Me}{ }_{2} \mathrm{CO} \cdot 0.5 \mathrm{C}_{7} \mathrm{H}_{16}$ and $\left[\mathrm{Co} 3(\mathrm{Piv})_{2} \mathrm{~L}_{2}{ }_{2} \mathrm{~L}_{2}^{2}\right] \cdot 2 \mathrm{Me} 2 \mathrm{CO}$ that can hardly be separated.

The pentanuclear molecule has three different environments of Co atoms: tetrahedral for the "central" $\mathrm{Co}$, octahedral for the "internal" $\mathrm{Co}_{2}$ and $\mathrm{Co}_{4}$ and trigonal bipyramidal for the "terminal" $\mathrm{Co}_{1}$ and $\mathrm{Co}_{5}$ (Figure 2).

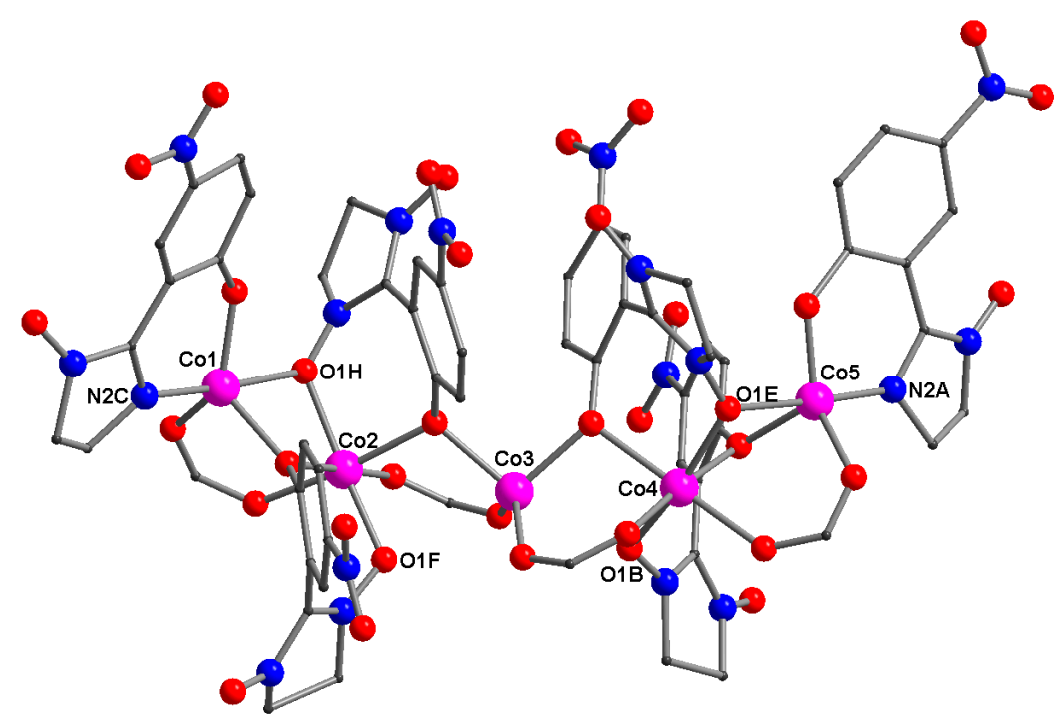

Figure 2. Structure of the pentanuclear $\left[\mathrm{Cos}(\operatorname{Piv}) 4 \mathrm{~L}^{1}{ }_{4} \mathrm{~L}^{2}\right]$ molecule.

The [Cos(Piv) $\left.{ }_{4} \mathrm{~L}_{4}^{1} \mathrm{~L}^{2}{ }_{2}\right]$ molecule contains fragments similar to those of [Co3( $\left.\mathrm{Piv}\right)_{2} \mathrm{~L}_{2}^{1} \mathrm{~L}_{2}^{2}$ ]; namely, the environment of the $\mathrm{Co} 1$ and $\mathrm{Co} 5$ atoms in Figure 2 is the same as that of $\mathrm{Co}_{1}$ in Figure 1; the environment of $\mathrm{Co}_{2}$ and $\mathrm{Co}_{4}$ in Figure 2 is the same as that of $\mathrm{Co}_{2}$ in Figure 1. In [Co5(Piv) ${ }_{4} \mathrm{~L}^{1}{ }_{4} \mathrm{~L}^{2}$ ] molecules, as well as in $\left[\mathrm{Co}_{3}(\mathrm{Piv})_{2} \mathrm{~L}_{2}{ }_{2} \mathrm{~L}_{2}^{2}\right]$ molecules, the "terminal" cobalt atoms ( $\mathrm{Co} 1$ and $\left.\mathrm{Co} 5\right)$ form six-membered metallocycles typical for Schiff bases with the coordinated imino nitroxides, and the $\mathrm{Co} 2$ and $\mathrm{Co} 4$ atoms form seven-membered metallocycles with nitronyl nitroxides. All of the Oph atoms of the phenoxy groups $\mathrm{L}^{1}$ perform the bridging function. Half of all nitroxyl $\mathrm{O}_{\mathrm{NO}}$ atoms $(\mathrm{O} 1 \mathrm{E}$ and $\mathrm{O} 1 \mathrm{H})$ are also involved in the formation of bridging bonds, while the other half $(\mathrm{O} 1 \mathrm{~B}$ and $\mathrm{O} 1 \mathrm{~F})$ are coordinated as monodentate ligands by the $\mathrm{Co}_{2}$ and $\mathrm{Co} 4$ atoms, respectively. The $\mathrm{Co}-\mathrm{N}$ bond lengths are 2.039(5) and 2.041(7) Å; 
the $\mathrm{Co}-\mathrm{O}$ bond lengths are 1.909(5)-2.269(5) $\AA$. The $\mathrm{Co}-\mathrm{O} 1 \mathrm{~B}$ and $\mathrm{Co}-\mathrm{O} 1 \mathrm{~F}$ distances are long enough, 2.580(4) and 2.836(5) $\AA$; as a result, the "central" Co3 atom has a tetrahedral environment.

Earlier, it was reported [23] that when $\mathrm{HL}^{2}$ reacted with nickel pivalate [ $\left.\mathrm{Ni}_{2}\left(\mathrm{H}_{2} \mathrm{O}\right)(\mathrm{Piv})_{4}(\mathrm{HPiv})_{4}\right]$, imino nitroxide did not undergo any transformations. When $\mathrm{Ni}(\mathrm{II})$ pivalate reacted with $\mathrm{HL}^{1}$, nitronyl nitroxide also did not undergo any redox transformations. Moreover, no products of interaction of Ni(II) pivalate with $\mathrm{L}^{1}$ were isolated irrespective of the starting reagent ratio and synthesis conditions (when the solution was concentrated, the solid product was primarily unchanged $\mathrm{HL}^{1}$ ). The introduction of both $\mathrm{HL}^{1}$ and $\mathrm{HL}^{2}$ in the reaction system, however, led to the formation of a mixed-ligand complex $\left.\left[\mathrm{Ni}_{3} \mathrm{~L}^{1} \mathrm{~L}_{2}^{2} \text { (Piv) }\right)_{3}(\mathrm{HPiv})_{3}\right]$, as in the case of cobalt. The highest yield of the complex $(60 \%)$ can be achieved when using the molar ratio of reagents $\left[\mathrm{Ni}_{2}\left(\mathrm{H}_{2} \mathrm{O}\right)(\mathrm{Piv})_{4}(\mathrm{HPiv})_{4}\right]: \mathrm{HL}^{1}: \mathrm{HL}^{2}=3: 2: 4$ corresponding to the stoichiometric coefficients of the reaction:

$$
3\left[\mathrm{Ni}_{2}\left(\mathrm{H}_{2} \mathrm{O}\right)(\mathrm{Piv})_{4}(\mathrm{HPiv})_{4}\right]+2 \mathrm{HL}^{1}+4 \mathrm{HL}^{2}=2\left[\mathrm{Ni}_{3} \mathrm{~L}^{1} \mathrm{~L}^{2} 2(\mathrm{Piv})_{3}(\mathrm{HPiv})_{3}\right]+12 \mathrm{HPiv}+3 \mathrm{H}_{2} \mathrm{O}
$$

The structure and composition of $\left.\left[\mathrm{Ni}_{3} \mathrm{~L}^{1} \mathrm{~L}^{2} 2 \text { (Piv) }\right)_{3}(\mathrm{HPiv})_{3}\right]$ differ from those for the trinuclear $\mathrm{Co}(\mathrm{II})$ complex with $\mathrm{L}^{1}$ and $\mathrm{L}^{2}$ ( $c f$. Figures 1 and 3). All of the Ni atoms have an octahedral environment. The paramagnetic ligands perform the bridging cyclic tridentate function. Each monodentate coordinated HPiv molecule forms an $\mathrm{H}$-bond with one of the $\mathrm{O}$ atoms of the neighboring $\mu_{2}-\mathrm{O}, \mathrm{O}^{\prime}$-pivalate anion. The Ni-N distances are 2.062(4) and 2.106(3) $\AA$; the Ni-O distances are 1.977(3) and 2.121(4) $\AA$.

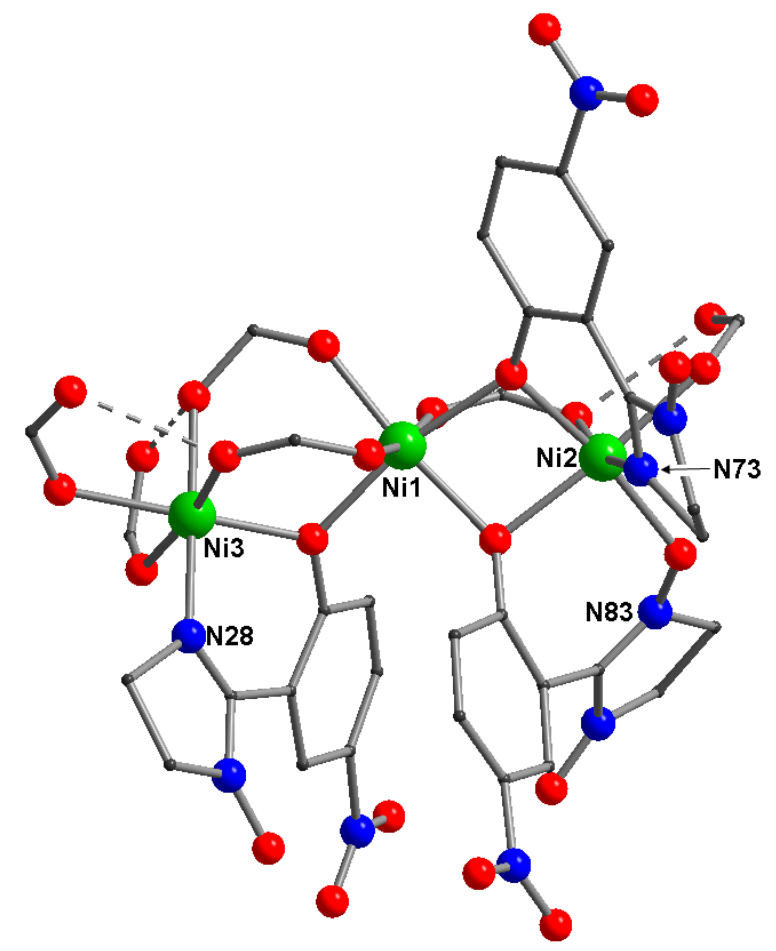

Figure 3. Molecular structure of $\left[\mathrm{Ni}_{3} \mathrm{~L}^{1} \mathrm{~L}^{2}{ }_{2}(\mathrm{Piv})_{3}(\mathrm{HPiv})_{3}\right]$.

Thus, the factors that favor the synthesis of $\left[\mathrm{Co} 5(\mathrm{Piv})_{4} \mathrm{~L}^{1}{ }_{4} \mathrm{~L}^{2}\right]$ by the reaction of $\mathrm{Co}$ (II) pivalate with $\mathrm{L}^{1}$ are the ability of the metal to be at different oxidation levels and the kinetic stability of both the starting $\mathrm{L}^{1}$ and the formed $\mathrm{L}^{2}$. When $\mathrm{Ni}(\mathrm{II})$ pivalate was used in the reaction with $\mathrm{L}^{1}$, the complexes containing $\mathrm{L}^{2}$ were never recorded. This is fully consistent with the data of [23-27], where the authors also used the metals capable of changing the oxidation level. 
Regarding the redox processes with nitroxides, it was noted that in the reaction with a transition metal, the nitroxide can be reduced to the corresponding hydroxylamine [28,29] and form the product of cocrystallization of the starting radical and the complex with nitrone [30] or complex with coordinated hydroxylamine [31]. $\mathrm{Co}(\mathrm{hfac})_{2}$ is able to reduce the ferrocenyl bis(nitronyl nitroxide) with producing the diamagnetic ferrocenyl bis(amidine oxide) cation, which forms with the $\left[\mathrm{Co}(\mathrm{hfac})_{3}\right]^{-}$, as the counterion, the complex salt [32]. Several products are known in which hydroxylamine reduced the metal and was itself oxidized to the corresponding nitroxide [33]. When the products of the interactions of metals with dinitroxides were studied, unusual compounds were isolated, in which one of the nitroxyl groups was reduced to the hydroxylamine anion during the reaction [24,25,34]. The oxidation of the transition metal induced by the reduction of one of the coordinated nitroxides was described in [26,27]. A specific copper(II)-nitroxide complex was described, which has a nontrivial structural peculiarity: it contains both the coordinated $\mathrm{O}$ atoms of nitroxide and those of the corresponding hydroxylamine anion [35]. An interesting manganese(II)-nitroxide-hydroxylamine complex was known, as well [36]. In the case of the interaction of transition metal compounds with $\mathrm{L}^{2}$ [23] and of $\mathrm{Co}$ (II) pivalate with $\mathrm{L}^{1}$, we found that heterospin complexes could be obtained, which contained both the starting nitroxide and the product of its reduction as a result of the transition metal-catalyzed transformation of the starting radical.

The pathway of the ligand reduction has not been established, but it is probably not a simple process $[28,31,32,34]$. However, the redox process can be suppressed in the synthesis of heterospin compounds of transition metals containing both nitronyl nitroxide and imino nitroxide or imino nitroxide and the corresponding nitrone (or hydroxylamine). Since nitronyl nitroxide, imino nitroxide and the corresponding nitrone are often kinetically stable and can be isolated in the individual state, a known mixture of components can be used in the synthesis, as was done in the case of the synthesis of $\left[\mathrm{Co}_{3}(\mathrm{Piv})_{2} \mathrm{~L}_{2}{ }_{2} \mathrm{~L}_{2}{ }_{2}\right]$ and $\left.\left[\mathrm{Ni}_{3} \mathrm{~L}^{1} \mathrm{~L}_{2}^{2} \text { (Piv) }\right)_{3}(\mathrm{HPiv})_{3}\right]$. This is especially important in the latter case. Since $\mathrm{Ni}(\mathrm{II})$ does not initiate the transformation of $\mathrm{L}^{1}$ into $\mathrm{L}^{2},\left[\mathrm{Ni}_{3} \mathrm{~L}^{1} \mathrm{~L}_{2}^{2}(\mathrm{Piv})_{3}(\mathrm{HPiv})_{3}\right]$ cannot be synthesized by any other procedure. Therefore, this is actually a new method for the synthesis of heterospin complexes: the reaction of a metal compound with a mixture of nitronyl nitroxide and imino nitroxide or with a mixture of imino nitroxide and the corresponding nitrone.

The multispin molecules of the multinuclear complexes in question have a rather complex system of exchange channels, which requires a separate detailed study in each case. Since this study concentrated on the new approach to the synthesis of heterospin complexes, the magnetic properties of the isolated products are presented below in concise fractographic form.

For $\left[\mathrm{Co}_{3}(\mathrm{Piv})_{2} \mathrm{~L}_{2}{ }_{2} \mathrm{~L}_{2}^{2}\right] \cdot 2 \mathrm{Me}_{2} \mathrm{CO}, \mu_{\mathrm{eff}}$, which is $8.09 \mu_{\mathrm{B}}$ at $300 \mathrm{~K}$, gradually increased to $10.57 \mu_{\mathrm{B}}$ when the temperature decreased to $8 \mathrm{~K}$ (Figure 4a). In the temperature range 100-300 K, the dependence $1 / \chi(\mathrm{T})$ obeys the Curie-Weiss law. The optimum values of the Curie $(\mathrm{C})$ and Weiss $(\theta)$ constants are $7.54 \pm 0.03 \mathrm{~cm}^{3} \cdot \mathrm{K} / \mathrm{mol}$ and $25.4 \pm 0.8 \mathrm{~K}$, respectively. The positive value of the Weiss constant $\theta$ suggests that the ferromagnetic exchange interactions are dominant. For [ $\left.\mathrm{Co} 3(\mathrm{Piv})_{2} \mathrm{~L}_{2}{ }_{2} \mathrm{~L}_{2}{ }_{2}\right] \cdot 2 \mathrm{Me}{ }_{2} \mathrm{CO}$, the dependence of magnetization on the strength of the external magnetic field below $14 \mathrm{~K}$ is nonlinear and cannot be described in terms of the Brillouin function (Figure $4 \mathrm{~b}$ ). This points to the transition of the substance into the magnetically-ordered state with spontaneous magnetization $26,000 \mathrm{~cm}^{3} \cdot \mathrm{G} / \mathrm{mol}$ at $2 \mathrm{~K}$. The Curie temperature $\mathrm{T}_{\mathrm{C}}$ can be estimated at $5 \mathrm{~K}$. 


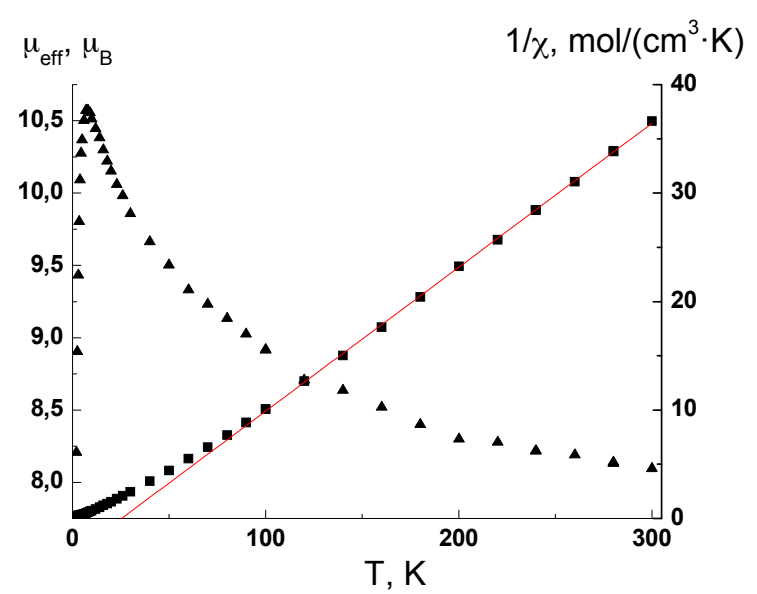

(a)

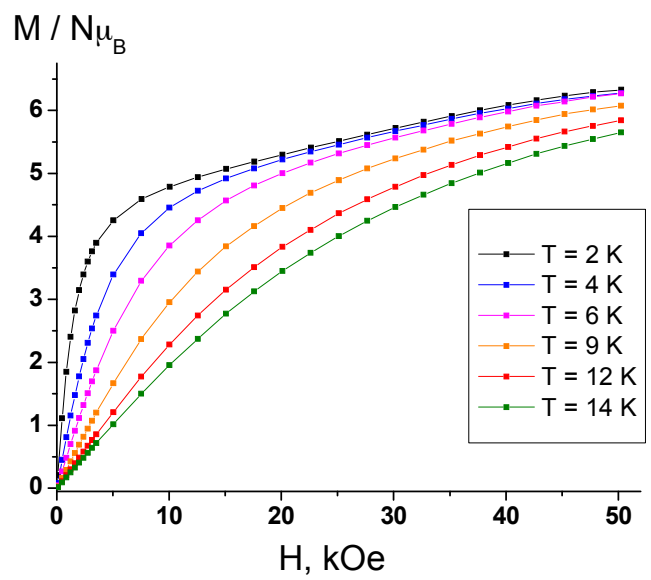

(b)

Figure 4. Temperature dependences of $\mu_{\text {eff }}$ and $1 / \chi($ a) and $\mathrm{M}(\mathrm{H})$ at different temperatures (b) for $\left[\mathrm{Co}_{3}(\mathrm{Piv})_{2} \mathrm{~L}_{2}{ }_{2} \mathrm{~L}_{2}\right] \cdot 2 \mathrm{Me}{ }_{2} \mathrm{CO}$.

For $\left[\mathrm{Co} 5(\mathrm{Piv}){ }_{4} \mathrm{~L}_{2}{ }_{2} \mathrm{~L}_{4}\right] \cdot 0.5 \mathrm{Me}_{2} \mathrm{CO} \cdot 0.5 \mathrm{C}_{7} \mathrm{H}_{16}, \mu_{\text {eff }}$ is $9.99 \mu_{\mathrm{B}}$ at $300 \mathrm{~K}$ and gradually increased to 14.85 $\mu_{\mathrm{B}}$ when the temperature decreased to $8 \mathrm{~K}$; then, it decreased abruptly to $11.17 \mu_{\mathrm{B}}$ at $2 \mathrm{~K}$. Note that the high-temperature value of $\mu_{\text {eff }}$ is considerably higher than the theoretical pure spin value of $7.55 \mu_{\mathrm{B}}$ for nine non-interacting paramagnetic centers (three $\mathrm{Co}(\mathrm{II})$ ions $(\mathrm{S}=3 / 2, \mathrm{~g}=2$ ) and four nitroxides $(\mathrm{S}=1 / 2, \mathrm{~g}=2)$ ) due to the orbital contribution that is typical for $\mathrm{Co}(\mathrm{II})$ ions in an octahedral environment. In the temperature range $100-300 \mathrm{~K}$, the dependence $1 / \chi(\mathrm{T})$ obeys the Curie-Weiss law. The optimum values of the Curie (C) and Weiss $(\theta)$ constants are $11.07 \pm 0.04 \mathrm{~cm}^{3} \cdot \mathrm{K} / \mathrm{mol}$ and $32.8 \pm 0.6 \mathrm{~K}$, respectively. For $\left[\mathrm{Co} 5(\mathrm{Piv})_{4} \mathrm{~L}_{2}{ }_{2} \mathrm{~L}^{2} 4\right] \cdot 0.5 \mathrm{Me}_{2} \mathrm{CO} \cdot 0.5 \mathrm{C}_{7} \mathrm{H}_{16}$, the dependence of magnetization on the strength of the external magnetic field below $10 \mathrm{~K}$ is nonlinear. A study of the magnetic susceptibility of $\left[\mathrm{Co} 5(\mathrm{Piv})_{4} \mathrm{~L}_{2}{ }_{2} \mathrm{~L}^{2}{ }_{4}\right] \cdot 0.5 \mathrm{Me}_{2} \mathrm{CO} \cdot 0.5 \mathrm{C}_{7} \mathrm{H}_{16}$ in an alternating magnetic field (Figure 5) showed that the temperature dependence of the out-of-phase component of magnetic-susceptibility $\chi^{\prime \prime}(\mathrm{T})$ has a maximum, which shifts toward low temperatures when the frequency of the alternating magnetic field decreases. The appearance of the out-of-phase component $\chi^{\prime \prime}(\mathrm{T})$ is one of the characteristics of single-molecule magnets (SMM). The maximum of $\chi^{\prime \prime}$ was not observed for all frequencies; the rough estimation of the energy barrier $\left(E_{a}\right)$ based on the Arrhenius equation $\ln (2 \pi v)=\ln \left(1 / \tau_{0}\right)+E_{a} /\left(k_{B} T\right)$ gave $\mathrm{E}_{\mathrm{a}} / \mathrm{k}_{\mathrm{B}}=3.1 \mathrm{~K}$. 


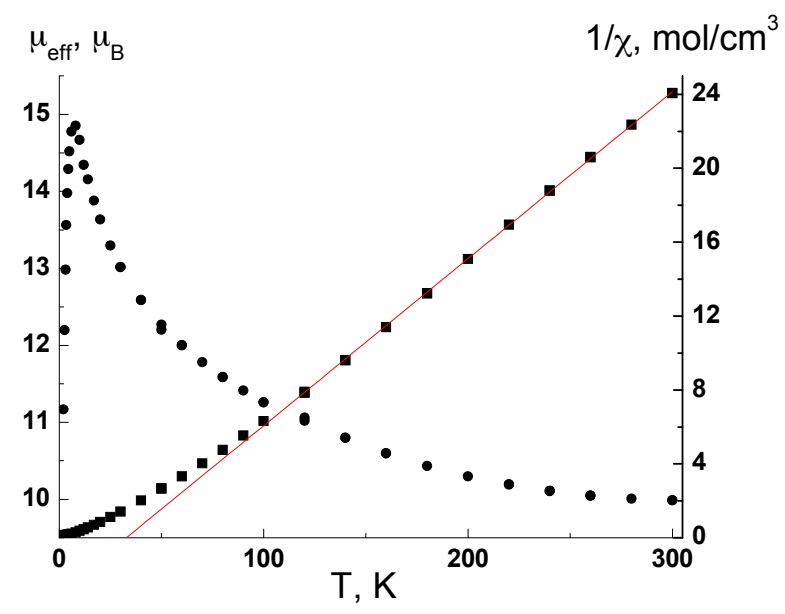

(a)

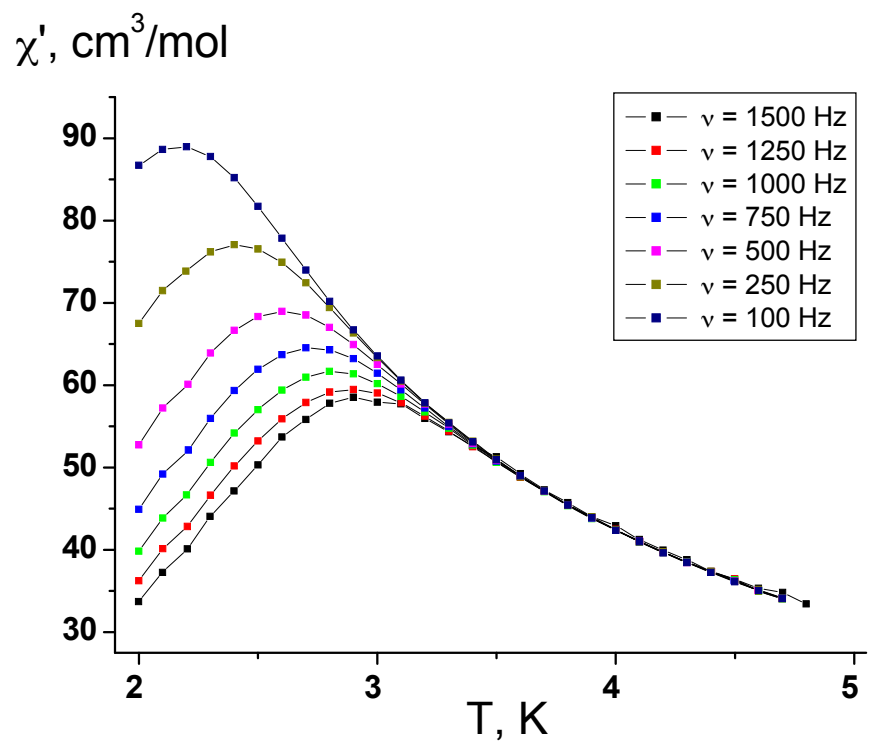

(b)

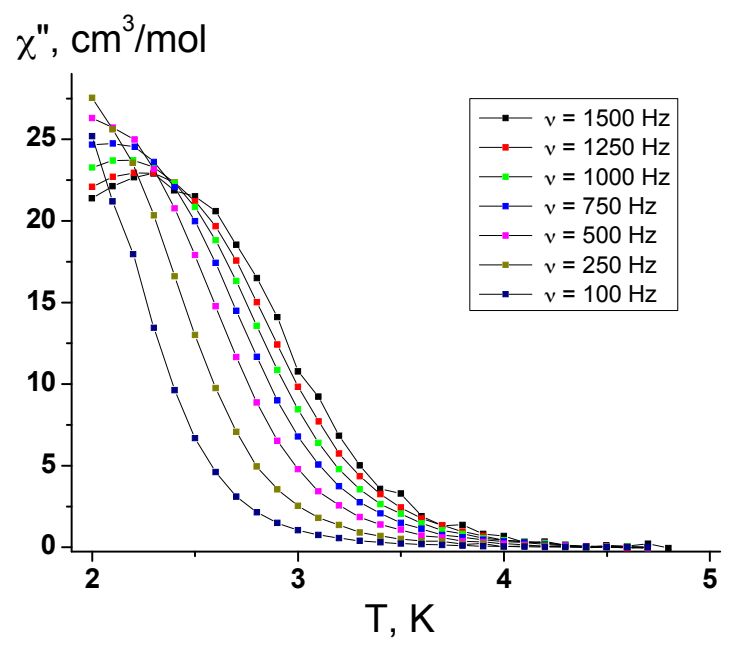

(c)

Figure 5. Temperature dependences of $\mu_{\mathrm{eff}}$ and $1 / \chi(\mathbf{a})$ and plot of the in-phase $\chi^{\prime}(\mathbf{b})$ and out-of-phase $\chi^{\prime \prime}(\mathbf{c})$ components of AC susceptibility at different frequencies $(v)$ as a function of temperature for $\left[\mathrm{Co}\right.$ (Piv) $\left.{ }_{4} \mathrm{~L}^{1}{ }_{2} \mathrm{~L}^{2}{ }_{4}\right] \cdot 0.5 \mathrm{Me}_{2} \mathrm{CO} \cdot 0.5 \mathrm{C}_{7} \mathrm{H}_{16}$. 
The dependence $\mu_{\text {eff }}(\mathrm{T})$ for $\left[\mathrm{Ni}_{3} \mathrm{~L}_{2}{ }_{2} \mathrm{~L}^{2}(\mathrm{Piv})_{3}(\mathrm{HPiv})_{3}\right]$ is presented in Figure 6 . The $\mu_{\text {eff }}$ value at $300 \mathrm{~K}$ is $6.01 \mu \mathrm{B}$ and does not change when the temperature decreases to $100 \mathrm{~K}$. Below $100 \mathrm{~K}$, $\mu$ eff gradually increases, reaching $6.32 \mu_{\mathrm{B}}$ at $10 \mathrm{~K}$, and then abruptly decreases to $5.28 \mu_{\mathrm{B}}$ at $2 \mathrm{~K}$. In the temperature range $10-300 \mathrm{~K}$, the dependence $1 / \chi(\mathrm{T})$ obeys the Curie-Weiss law. The optimum values of the Curie (C) and Weiss $(\theta)$ constants are $4.45 \pm 0.01 \mathrm{~cm}^{3} \cdot \mathrm{K} / \mathrm{mol}$ and $2.4 \pm 0.2 \mathrm{~K}$, respectively. The high-temperature value of $\mu_{\text {eff }}$ agrees well with the theoretical pure spin value $5.74 \mu_{\mathrm{B}}$ for six non-interacting paramagnetic centers (three $\mathrm{Ni}$ (II) ions with spin $\mathrm{S}=1$ and three nitroxides with spins $\mathrm{S}=1 / 2$ at a $\mathrm{g}$ factor of two. The increased $\mu_{\text {eff }}$ at lower temperatures and the positive Weiss constant $\theta$ indicate that weak ferromagnetic exchange interactions between the spins of the paramagnetic centers dominate.

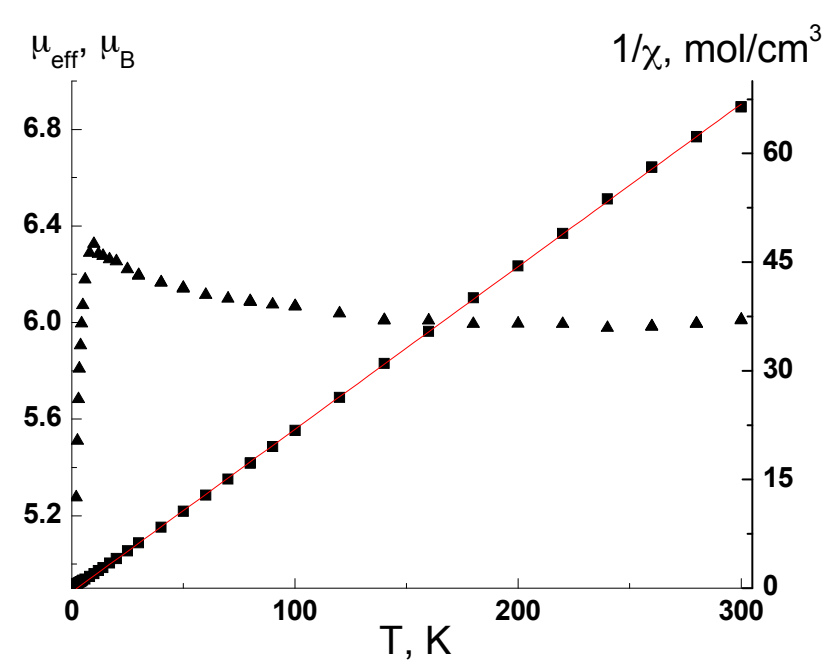

Figure 6. Temperature dependences of $\mu_{\text {eff }}$ and $1 / \chi$ for $\left[\mathrm{Ni}_{3} \mathrm{~L}^{1}{ }_{2} \mathrm{~L}^{2}(\mathrm{Piv})_{3}(\mathrm{HPiv})_{3}\right]$.

\section{Experimental Section}

The binuclear pivalates $\left[\mathrm{Co}_{2}\left(\mathrm{H}_{2} \mathrm{O}\right)(\mathrm{Piv})_{4}(\mathrm{HPiv})_{4}\right]$ and $\left[\mathrm{Ni}_{2}\left(\mathrm{H}_{2} \mathrm{O}\right)(\mathrm{Piv})_{4}(\mathrm{HPiv})_{4}\right]$ were prepared as described in [37]. The synthesis of $\mathrm{HL}^{1}$ and $\mathrm{HL}^{2}$ was described in [38].

\subsection{Synthesis of $\left[\mathrm{CO}_{3}(\mathrm{Piv})_{2} \mathrm{~L}_{2} \mathrm{~L}_{2}^{2}\right] \cdot 2 \mathrm{Me}{ }_{2} \mathrm{CO}$}

A solution of a mixture of $\mathrm{HL}^{1}(0.021 \mathrm{~g}, 0.07 \mathrm{mmol})$ and $\mathrm{HL}^{2}(0.02 \mathrm{~g}, 0.07 \mathrm{mmol})$ in acetone $(3 \mathrm{~mL})$ was added to the solution of $\left[\mathrm{Co}_{2}\left(\mathrm{H}_{2} \mathrm{O}\right)(\mathrm{Piv})_{4}(\mathrm{HPiv})_{4}\right](0.05 \mathrm{~g}, 0.053 \mathrm{mmol})$ in acetone $(2 \mathrm{~mL})$ at room temperature. Then, heptane $(3 \mathrm{~mL})$ was added to the reaction mixture, and the mixture was stirred until it became transparent. The reaction mixture was kept in an open flask for 2 days. Its volume decreased, and brown prismatic crystals precipitated, which were filtered off, washed with a cooled mixture of acetone and heptane (1:3) and dried with an air current. Yield 70\%. Anal. calcd. for $\mathrm{C}_{68} \mathrm{H}_{90} \mathrm{~N}_{12} \mathrm{Co}_{3} \mathrm{O}_{24}(\%)$ : C, 49.9; H, 5.5; N, 10.3. Found (\%): C, 49.8; H, 5.4; N, 10.0. 


\subsection{Synthesis of $\left[\mathrm{Cos}(\mathrm{Piv})_{4} \mathrm{~L}_{4} \mathrm{~L}^{2}{ }_{2}\right] \cdot 0.5 \mathrm{Me}_{2} \mathrm{CO} \cdot 0.5 \mathrm{C}_{7} \mathrm{H}_{16}$}

A solution of $\mathrm{HL}^{1}(0.025 \mathrm{~g}, 0.084 \mathrm{mmol})$ in acetone $(2 \mathrm{~mL})$ was added to the solution of $\left[\mathrm{Co}_{2}\left(\mathrm{H}_{2} \mathrm{O}\right)(\mathrm{Piv})_{4}(\mathrm{HPiv})_{4}\right](0.04 \mathrm{~g}, 0.042 \mathrm{mmol})$ in acetone $(3 \mathrm{~mL})$ at room temperature. Then, heptane $(3 \mathrm{~mL})$ was added, and the mixture was stirred until the solution became transparent. After the solution was kept for 2 or 3 days, brown elongated crystals precipitated. They were filtered off, washed with cold acetone and dried with an air current. Yield 50\%-60\%. Anal. calcd. for $\mathrm{C}_{206} \mathrm{H}_{274} \mathrm{~N}_{36} \mathrm{Co}_{10} \mathrm{O}_{73}(\%)$ : C, 49.4; H, 5.5; N, 10.1. Found (\%): C, 49.7; H, 5.6; N, 9.5.

$\left[\mathrm{Co} 5(\mathrm{Piv})_{4} \mathrm{~L}_{4} \mathrm{~L}^{2}{ }_{2}\right] \cdot 0.5 \mathrm{Me}_{2} \mathrm{CO} \cdot 0.5 \mathrm{C}_{7} \mathrm{H}_{16}$ also formed at an initial reagent ratio of $\left[\mathrm{Co}_{2}\left(\mathrm{H}_{2} \mathrm{O}\right)(\mathrm{Piv})_{4}(\mathrm{HPiv})_{4}\right]: \mathrm{HL}^{1}=1: 1$ or 1:4. In the former case, however, the crystals of the complex were contaminated with an unidentified blue gel-like product; in the latter case, with the crystals of excess nitroxide $\mathrm{HL}^{1}$. The highest yield of $\left[\mathrm{Co} 5(\mathrm{Piv})_{4} \mathrm{~L}^{1}{ }_{4} \mathrm{~L}^{2} 2\right] \cdot 0.5 \mathrm{Me}_{2} \mathrm{CO} \cdot 0.5 \mathrm{C}_{7} \mathrm{H}_{16}(70 \%)$ was obtained when binuclear $\mathrm{Co}$ (II) pivalate, $\mathrm{HL}^{1}$ and $\mathrm{HL}^{2}$ were used as the starting reagents in a ratio of 5:8:4, which corresponds to the stoichiometric coefficients of the reaction:

$$
5\left[\mathrm{Co}_{2}\left(\mathrm{H}_{2} \mathrm{O}\right) \mathrm{Piv}_{4}(\mathrm{HPiv})_{4}\right]+8 \mathrm{HL}^{1}+4 \mathrm{HL}^{2}=2\left[\mathrm{Co} 5(\mathrm{Piv})_{4} \mathrm{~L}_{4}{ }_{4} \mathrm{~L}^{2} 2\right]+32 \mathrm{HPiv}+5 \mathrm{H}_{2} \mathrm{O}
$$

\subsection{Synthesis of $\left[\mathrm{Ni}_{3} \mathrm{~L}^{1} \mathrm{~L}^{2}{ }_{2}(\mathrm{Piv})_{3}(\mathrm{HPiv})_{3}\right]$}

A mixture of $\left[\mathrm{Ni}_{2}\left(\mathrm{H}_{2} \mathrm{O}\right)(\mathrm{Piv})_{4}(\mathrm{HPiv})_{4}\right](0.05 \mathrm{~g}, 0.053 \mathrm{mmol}), \mathrm{HL}^{1}(0.01 \mathrm{~g}, 0.034 \mathrm{mmol})$ and $\mathrm{HL}^{2}$ $(0.019 \mathrm{~g}, 0.068 \mathrm{mmol})$ was dissolved in acetone $(3 \mathrm{~mL})$ in a dry $\mathrm{N}_{2}$ atmosphere at room temperature (MBraun chamber). Then, heptane $(5 \mathrm{~mL})$ was added to the resulting dark red solution. The reaction mixture was kept in an open flask for 3 or 4 days, after which dark claret red crystals were filtered off. Yield 77\%. Anal. calcd. for $\mathrm{C}_{69} \mathrm{H}_{102} \mathrm{Ni}_{3} \mathrm{~N}_{9} \mathrm{O}_{25}$ (\%): C, 50.7; H, 6.3; N, 7.7. Found (\%): C, 51.2; H, 6.5; N, 7.6.

\subsection{Crystal Structure Determination}

The X-ray diffraction (XRD) experiments were performed on a SMART APEX II CCD and APEX DUO (Bruker AXS) diffractometer (Mo Ka for Co complexes and $\mathrm{Cu} \mathrm{K \alpha}$ for the Ni complex). All of the structures were solved by direct methods and refined by full-matrix least-squares analysis in an anisotropic approximation for non-hydrogen atoms. The positions of the majority of $\mathrm{H}$ atoms were calculated. The methyl $\mathrm{H}$ atoms were refined isotropically in a rigid group approximation. Hydrogen atoms were refined isotropically with the use of geometrical constraints. Since the solvent molecules in $\left\{\mathrm{Co}_{5}\right\}$ and $\left\{\mathrm{Ni}_{3}\right\}$ complexes could not be modeled properly, they were squeezed out with PLATON [27,39]. All calculations were performed with the Bruker SHELXTL (Version 6.14) and SHELXL (Version 2014/6) program packages [40]. The crystal data and details of experiments are given in Table 1. Crystallographic data were deposited with the Cambridge Crystallographic Data Centre and can be obtained free of charge via www.ccdc.cam.ac.uk/getstructures. 
Table 1. Crystal data and the details of the experiments for the complexes.

\begin{tabular}{|c|c|c|c|}
\hline Compound & {$\left[\mathrm{Co}_{3}(\mathrm{Piv})_{2} \mathrm{~L}_{2}{ }_{2} \mathrm{~L}^{2}{ }_{2}\right] \cdot 2 \mathrm{Me}_{2} \mathrm{CO}$} & {$\left[\mathrm{Co}_{5}(\mathrm{Piv})_{4} \mathrm{~L}_{4}{ }_{4} \mathrm{~L}_{2}{ }_{2}\right]$} & {$\left[\mathrm{Ni}_{3} \mathrm{~L}^{1} \mathbf{L}_{2}{ }_{2}(\mathrm{Piv})_{3}(\mathrm{HPiv})_{3}\right]$} \\
\hline FW & 1636.30 & 2426.82 & 1633.73 \\
\hline $\mathrm{T}, \mathrm{K}$ & 240 & 296 & 240 \\
\hline Space group, $Z$ & $C 2 / c, 4$ & $P 2_{1} / c, 4$ & $P 2_{1} / c, 4$ \\
\hline$a, \AA$ & $20.3249(15)$ & $21.7158(6)$ & $25.791(3)$ \\
\hline$b, \AA$ & $17.0770(14)$ & $21.4802(6)$ & $16.4283(18)$ \\
\hline$c, \AA$ & $23.602(3)$ & $28.1954(7)$ & $23.722(2)$ \\
\hline$\beta,{ }^{\circ}$ & $106.553(6)$ & $103.044(2)$ & $116.538(5)$ \\
\hline$V, \AA^{3}$ & $7852.3(12)$ & $12812.6(6)$ & $8991.9(17)$ \\
\hline$D_{\mathrm{c}}, \mathrm{g} \cdot \mathrm{cm}^{-3}$ & 1.384 & 1.258 & 1.207 \\
\hline$\theta_{\max }, \circ$ & 28.008 & 28.331 & 67.628 \\
\hline$I_{\mathrm{hkl}}($ meas/uniq) & $33,218 / 9349$ & $117,351 / 31,674$ & $67,564 / 15,783$ \\
\hline$R_{\text {int }}$ & 0.1338 & 0.1363 & 0.1176 \\
\hline$I_{\mathrm{hkl}}(\mathrm{obs})$ & 3110 & 8829 & 6251 \\
\hline Parameters & 520 & 1507 & 956 \\
\hline GooF & 0.751 & 0.898 & 0.851 \\
\hline$R_{1} / w R_{2}\left(I>2 \sigma_{I}\right)$ & $0.0462 / 0.757$ & $0.0777 / 0.1948$ & $0.0663 / 0.1669$ \\
\hline$R_{1} / w R_{2}$ (all data) & $0.1875 / 0.1013$ & $0.27481 / 0.2871$ & $0.1532 / 0.2064$ \\
\hline$\Delta \rho_{\max }, \Delta \rho_{\min } / \mathrm{e} \AA^{-3}$ & $0.363,-0.256$ & $0.711,-0.396$ & $0.643,-0.430$ \\
\hline CCDC deposition & 1419127 & 1419128 & 1419126 \\
\hline
\end{tabular}

\subsection{Magnetic Measurements}

The magnetic susceptibility of the polycrystalline samples was measured with a Quantum Design MPMSXL SQUID magnetometer in the temperature range 2-300 K with a magnetic field of up to $5 \mathrm{kOe}$. The diamagnetic corrections were made using the Pascal constants. The effective magnetic moment was calculated as $\mu_{\mathrm{eff}}(\mathrm{T})=\left[\left(3 \mathrm{k} / \mathrm{N}_{\mathrm{A}} \mu_{\mathrm{B}}{ }^{2}\right) \chi \mathrm{T}\right]^{1 / 2} \approx(8 \chi \mathrm{T})^{1 / 2}$. The AC magnetic susceptibility was measured in an oscillating AC field of $3.5 \mathrm{G}$ and a zero DC field. The oscillation frequencies were in the range $98-1488 \mathrm{~Hz}$.

\section{Conclusions}

Thus, our study showed that the reaction of $\mathrm{Co}(\mathrm{II})$ pivalate with nitronyl nitroxide $\mathrm{HL}^{1}$ forms a pentanuclear complex [Cos(Piv) ${ }_{4} \mathrm{~L}^{1}{ }_{4} \mathrm{~L}^{2}$ ], whose molecule has both the starting nitronyl nitroxide $\mathrm{L}^{1}$ and its imino nitroxide analog $\mathrm{L}^{2}$. This prompted us to introduce a known mixture of $\mathrm{HL}^{1}$ and $\mathrm{HL}^{2}$ in the reaction. It appeared that this synthetic technique (the use of both the starting radical and the product of its reduction in the reaction with the metal) can serve as an independent method for the synthesis of heterospin complexes. It was shown that the interaction of $\mathrm{Co}$ (II) pivalate with nitroxides at a molar ratio of reagents of $\left[\mathrm{Co}_{2}\left(\mathrm{H}_{2} \mathrm{O}\right)(\mathrm{Piv})_{4}(\mathrm{HPiv})_{4}\right]: \mathrm{HL}^{1}: \mathrm{HL}^{2}=3: 4: 4$ gives the trinuclear heterospin complex $\left[\mathrm{Co}_{3}(\mathrm{Piv})_{2} \mathrm{~L}_{2}{ }_{2} \mathrm{~L}^{2}{ }_{2}\right]$ with a high yield. The replacement of $\mathrm{Co}$ (II) by $\mathrm{Ni}$ (II) completely suppresses the reduction of $\mathrm{HL}^{1}$ into $\mathrm{HL}^{2}$. In addition, $\mathrm{Ni}(\mathrm{II})$ pivalate does not react with $\mathrm{HL}^{1}$. However, the use of the known mixture of $\mathrm{HL}^{1}$ and $\mathrm{HL}^{2}$ in the reaction with $\left[\mathrm{Ni}_{2}\left(\mathrm{H}_{2} \mathrm{O}\right) \mathrm{Piv}_{4}(\mathrm{HPiv})_{4}\right]$ is an effective method for the synthesis of the heterospin complex $\left[\mathrm{Ni}_{3} \mathrm{~L}^{1} \mathrm{~L}^{2}{ }_{2}(\mathrm{Piv})_{3}(\mathrm{HPiv})_{3}\right]$, which also contains both nitronyl and imino nitroxides. 
Thus, the results of the present study open up a new opportunity in the synthesis of heterospin complexes. Since both nitronyl and imino nitroxides and the corresponding nitrone (the product of more profound reduction) are generally kinetically-stable products, their binary mixtures can readily be prepared. The use of these mixtures in reactions with transition metals can lead to multispin complexes, including [ $\mathrm{Co}_{3}(\mathrm{Piv})_{2} \mathrm{~L}_{2}{ }_{2} \mathrm{~L}_{2}$ ] and $\left[\mathrm{Ni}_{3} \mathrm{~L}^{1} \mathrm{~L}^{2} 2\right.$ (Piv)3(HPiv)3], which were obtained only using the known mixture of nitronyl nitroxide and its imino nitroxide derivative as the starting reagent.

\section{Acknowledgments}

This study was financially supported by the Russian Science Foundation (Project 15-13-30012). Elena Fursova acknowledges the Russian Foundation for Basic Research (RFBR) for financial support of the synthesis of nitroxides (Project 15-03-00488) and Federal Agency for Scientific Organizations of Russia (FASO RF). Olga Kuznetsova acknowledges the RFBR for support of the synthesis of heterospin complexes (Grant 15-33-20286) and the President of the Russian Federation Grants Council (Grant MK-2732.2015.3). Galina Romanenko thanks the RFBR for partial support of the XRD studies (Grant 14-03-00517) and FASO RF. Artem Bogomyakov thanks the RFBR for partial support of magnetochemical measurements (Grant 15-53-10009).

\section{Author Contributions}

Olga Kuznetsova and Elena Fursova performed the experiments on the synthesis of heterospin complexes and the growth of high-quality crystals. Galina Romanenko carried out an X-ray diffraction study of the single crystals of the compounds. Artem Bogomyakov performed magnetochemical measurements. Victor Ovcharenko formulated the idea and wrote the manuscript, which was revised and accepted by all of the co-authors.

\section{Conflicts of Interest}

The authors declare no conflict of interest.

\section{References}

1. Volodarsky, L.B.; Reznikov, V.A.; Ovcharenko, V.I. Synthetic Chemistry of Stable Nitroxides; CRC Press: Boca Raton, FL, USA, 1994.

2. Hicks, R.G. Stable Radicals: Fundamentals and Applied Aspects of Odd-Electron Compounds; Wiley: Wiltshire, UK, 2010.

3. Hawker, C.J.; Bosman, A.W.; Harth, E. New polymer synthesis by nitroxide mediated living radical polymerizations. Chem. Rev. 2001, 101, 3661-3688.

4. Nicolas, J.; Guillaneuf, Y.; Lefay, C.; Bertin, D.; Gigmes, D.; Charleux, B. Nitroxide-mediated polymerization. Prog. Polym. Sci. 2013, 38, 63-235.

5. Nishide, H.; Oyaizu, K. Toward flexible batteries. Science 2008, 319, 737-738.

6. Morita, Y.; Nishida, S.; Murata, T.; Moriguchi, M.; Ueda, A.; Satoh, M.; Arifuku, K.; Sato, K.; Taku, T. Organic tailored batteries materials using stable open-shell molecules with degenerate frontier orbitals. Nat. Mater. 2011, 10, 947-951. 
7. Kahn, M.L.; Sutter, J.-P.; Golhen, S. Systematic Investigation of the Nature of The Coupling between a $\mathrm{Ln}$ (III) Ion ( $\mathrm{Ln}=\mathrm{Ce}(\mathrm{III})$ to $\mathrm{Dy}(\mathrm{III}))$ and Its Aminoxyl Radical Ligands. Structural and Magnetic Characteristics of a Series of $\{\operatorname{Ln}($ organic radical) 2$\}$ Compounds and the Related \{Ln(Nitrone)2\} Derivatives. J. Am. Chem. Soc. 2000, 122, 3413-3421.

8. Ovcharenko, V.I.; Fursova, E.Y.; Tolstikova, T.G.; Sorokina, K.N.; Letyagin, A.Y.; Savelov, A.A. Imidazol-4-yl 2-Imidazoline Nitroxide Radicals, a New Class of Promising Contrast Agents for Magnetic Resonance Imaging. Dokl. Chem. 2005, 404, 171-173.

9. Hyodo, F.; Matsumoto, K.; Matsumoto, A.; Mitchell, J.B.; Krishna, M.C. Probing the Intracellular Redox Status of Tumors with Magnetic Resonance Imaging and Redox-Sensitive Contrast Agents. Cancer Res. 2006, 66, 9921-9928.

10. Caneschi, A.; Gatteschi, D.; Sessoli, R.; Rey, P. Toward molecular magnets: the metal-radical approach. Acc. Chem. Res. 1989, 22, 392-398.

11. Iwamura, H.; Inoue, K.; Hayamizu, T. High-spin polynitroxide radicals as versatile bridging ligands for transition metal complexes with high ferri/ferromagnetic TC. Pure Appl. Chem. 1996, 68, $243-252$.

12. Iwamura, H.; Inoue, K. Magnetic Ordering in Metal Coordination Complexes with Aminoxyl Radicals. In Magnetism: Molecules to Materials II. Molecule-Based Materials; Miller, J.S., Drillon, M., Eds.; Wiley-VCH: Weinheim, Germany, 2001; pp. 61-108.

13. Luneau, D.; Rey, P. Magnetism of metal-nitroxide compounds involving bis-chelating imidazole and benzimidazole substituted nitronyl nitroxide free radicals. Coord. Chem. Rev. 2005, 249, 2591-2611.

14. Sato, O.; Tao J.; Zhang, Y-Z. Control of magnetic properties through external stimuli. Angew. Chem. Int. Ed. 2007, 46, 2152-2187.

15. Ovcharenko, V. Metal-Nitroxide Complexes: Synthesis and Magnetostructural Correlations. In Stable Radicals: Fundamentals and Applied Aspects of Odd-Electron Compounds; Hicks, R.G., Ed.; Wiley: Wiltshire, Germany, 2010; pp. 461-506.

16. Roubeau, O.; Clérac, R. Rational Assembly of High-Spin Polynuclear Magnetic Complexes into Coordination Networks: The Case of a [Mn4] Single-Molecule Magnet Building Block. Eur. J. Inorg. Chem. 2008, 28, 4325-4342.

17. Ovcharenko, V.; Bagryanskaya, E. Breathing crystals from copper nitroxyl complexes. In Spin-Crossover Materials-Properties and Applications; Halcrow, M.A., Ed.; Wiley: Chichester, UK, 2013; pp. 239-280.

18. Likhtenshtein, G.I.; Jun Yamauchi, J.; Nakatsuji, S.; Smirnov, A.I.; Tamura, R. Nitroxides: Applications in Chemistry, Biomedicine, and Materials Science; WILEY-VCH: Weinheim, Germany, 2008.

19. Kokorin, A.I. Nitroxides: Theory, Experiment and Applications; InTech: Rijeka, Croatia, 2012.

20. Likhtenshtein, G.I. Nitroxides: 170 Years of History in Biology and Biomedicine. Int. Res. J. Pure Appl. Chem. 2015, 8, 1-18.

21. Bagryanskaya, E.G.; Marque, S.R.A. Scavenging of Organic C-Centered Radicals by Nitroxides. Chem. Rev. 2014, 114, 5011-5056.

22. Tebben, L.; Studer, A. Nitroxides: Applications in Synthesis and in Polymer Chemistry. Angew. Chem. Int. Ed. 2011, 50, 5034-5068. 
23. Ovcharenko, V.; Kuznetsova, O.; Fursova, E.; Romanenko, G.; Polushkin, A.; Sagdeev, R. Redox-Induced Change in the Ligand Coordination Mode. Inorg. Chem. 2014, 53, 10033-10035.

24. Ito, T.; Ohto, A.; Oshio, H.; Watanabe, T. A One-Dimensional Helical Copper(II) Imino Nitroxide. Inorg. Chem. 1997, 36, 1608-1610.

25. Furui, T.; Suzuki, S.; Kozaki, M.; Shiomi, D.; Sato, K; Takui, T.; Okada, K.; Tretyakov, E.; Tolstikov, S.; Romanenko, G.; et al. Preparation and magnetic properties of metal-complexes from N-t-butyl-N-oxidanyl-2-amino-(nitronyl nitroxide). Inorg. Chem. 2014, 53, 802-809.

26. Gass, I.A.; Gartshore, C.J.; Lupton, D.W.; Moubaraki, B.; Nafady, A.; Bond, A.M.; Boas, J.F.; Cashion, J.D.; Milsmann, C.; Wieghardt, K.; Murray, K.S. Anion dependent redox changes in iron bis-terdentate nitroxide $\{\mathrm{NNO}\}$ chelates. Inorg. Chem. 2011, 50, 3052-3064.

27. Gass, I.A.; Tewary, S.; Nafady, A.; Chilton, N.F.; Gartshore, C.J.; Asadi, M.; Lupton, D.W.; Moubaraki, B.; Bond, A.M.; Boas, J.F.; et al. Observation of ferromagnetic exchange, spin crossover, reductively induced oxidation, and field-induced slow magnetic relaxation in monomeric cobalt nitroxides. Inorg. Chem. 2013, 52, 7557-7572.

28. Carducci, M.D.; Doedens, R.J. Dimeric Complex of a Reduced Nitroxyl Radical with Bis(hexafluoroacetylacetonato)manganese(II). Inorg. Chem. 1989, 28, 2492-2494.

29. Jiang, Z.-H.; Sun, B.-W.; Liao, D.-Z.; Wang, G.-L.; Donnadieu, B.; Tuchagues, J.-P. Transition metal complexes with nitronyl nitroxides. Part 2. Crystal structure and magnetism of manganese(II) compounds including radicals and their reduced derivatives. Inorganica Chimica Acta 1998, 279, 76-84.

30. Caneschi, A.; Gatteschi, D.; Laugier, J.; Rey, P.; Zanchini, C. Synthesis, X-ray crystal structure, and magnetic properties of two dinuclear manganese(II) compounds containing nitronyl nitroxides, imino nitroxides, and their reduced derivatives. Inorg. Chem. 1989, 28, 1969-1975.

31. Ishida, T.; Suzuki, T.; Kaizaki, S. Synthesis and characterization of [Co( $\left.\left.\mathrm{NO}_{2}\right)_{2}(\mathrm{acac})(\mathrm{IMH} 2 \mathrm{py})\right]$ with one-electron-reduced imino nitroxide radical associated with unusual displacement of acetylacetonate in the starting complex trans $-\mathrm{Na}\left[\mathrm{Co}\left(\mathrm{NO}_{2}\right)_{2}(\mathrm{acac})_{2}\right]$. Inorganica Chimica Acta 2004, 357, 3134-3138.

32. Sporer, C.; Wurst, K.; Ruiz-Molina, D.; Kopacka, H.; Veciana, J.; Jaitner, P. Synthesis, X-ray structure and characterization of a novel $\left[\mathrm{fc}(\mathrm{IMH})_{2} \mathrm{H}\right]^{+}\left[\mathrm{Co}(\mathrm{hfac})_{3}\right]^{-}$salt with hydrogen bonded ferrocenyl bis(imino hydroxylamino) building blocks. J. Organomet. Chem. 2003, 684, 44-49.

33. Burdukov, A.B.; Ovcharenko, V.I.; Ikorskii, V.N.; Pervukhina, N.V.; Podberezskaya, N.V.; Grigor'ev, I.A.; Larionov, S.V.; Volodarsky, L.B. A new type of mixed-ligand complexes with nitroxyl radicals. Inorg. Chem. 1991, 30, 972-976.

34. Ruiz-Molina, D.; Sporer, C.; Wurst, K.; Jaitner, P.; Veciana, J. Spin Frustration in a Dimeric Mn ${ }^{\mathrm{II}}$ Complex with a Metallocene-Substituted $\alpha$-Nitronyl Nitroxide Radical. Angew. Chem. Int. Ed. 2000, 39, 3688-3691.

35. Okazawa, A.; Hashizume, D.; Ishida, T. Ferro- and antiferromagnetic coupling switch accompanied by twist deformation around the copper(II) and nitroxide coordination bond. J. Am. Chem. Soc. 2010, 132, 11516-11524.

36. Li, Y.; Guo, Y.; Tian, H.; Hu, P.; Sun, Z.; Ma, Y.; Li, L.; Liao, D. A unique tetranuclear Mn(II) cluster bridged by carboxyl substituted nitronyl nitroxide radical: Crystal structure and magnetic properties. Inorg. Chem. Commun. 2014, 43, 135-137. 
37. Mikhailova, T.B.; Fomina, I.G.; Sidorov, A.A.; Golovaneva, I.F.; Aleksandrov, G.G.; Novotortsev, V.M.; Ikorskiy, V.N.; Eremenko, I.L. A study of magnetic properties in binuclear complexes with $\{\mathrm{M}-2(\mu-\mathrm{OH} 2)(\mu-\mathrm{OOCCMe} 3) 2\}$ moiety $(\mathrm{M}=\mathrm{Co}(\mathrm{II}), \mathrm{Ni}(\mathrm{II}))$. Russ. J. Inorg. Chem. 2003, 48, 1505-1512. (In Russian)

38. Tretyakov, E.V.; Eltsov, I.V.; Fokin, S.V.; Shvedenkov, Y.G.; Romanenko, G.V.; Ovcharenko V.I. Synthesis of 2-iminonitroxide-substituted phenols and pyridine-3-oles. Copper(II) complexes with imino nitroxides containing 2-hydroxyphenyl substituents. Polyhedron 2003, 22, 2499-2514.

39. Spek, A.L. Structure validation in chemical crystallography. Acta Crystallogr. Sect. D: Biol. Crystallogr. 2009, D65, 148-155.

40. Sheldrick G.M. Crystal structure refinement with SHELXL. Acta Crystallogr. Sect. C 2015, 71, 3-8.

(C) 2015 by the author; licensee MDPI, Basel, Switzerland. This article is an open access article distributed under the terms and conditions of the Creative Commons Attribution license (http://creativecommons.org/licenses/by/4.0/). 